\title{
Monitoring fetal and infant survival using regional birth notification data in north east London
}

\author{
Lisa Hilder, Eva Alberman
}

\begin{abstract}
Objective-To demonstrate the use of aggregated, locally collected birth notification data to examine trends in birthweight specific survival for singleton and multiple births.

Design-Retrospective analysis of 171527 notified births and subsequent infant survival data derived from computerised community child health records. Validation of data completeness and quality was undertaken by comparison with birth and death registration records for the same period.

Setting-Notifications of births in 19891991 to residents of the North Thames (East) Region (formerly North East Thames Regional Health Authority). Outcome measures-Birthweight specific stillbirth, neonatal, and postneonatal death rates.

Results-There was close correspondence between the notification and registration data. For $96 \%$ of the registered deaths a birth notification record was identified and for the majority of these the death was already known to the Community Child Health Computer. Completeness of birthweight data, particularly at the lower end of the range, was substantially better in birth notification data. Comparison with the most recent published national data relating to birthweight specific survival of very low birthweight singleton and multiple births suggests that the downward trend of mortality is continuing, at least in this Region.

Conclusions-The use of routinely collected aggregated birth notification data provides a valuable adjunct to existing sources of information about perinatal and infant survival, as well as other information regarding process and outcome of maternity services. Such data are required for comparative audit and may be more complete than that obtained from registration or hospital generated data.
\end{abstract}

(F Epidemiol Community Health 1998;52:253-258)

The monitoring of birthweight specific incidence and mortality trends remains important because of the need to audit developments in medical care of high risk births and concern about the long term outcome of those of very low birth weight. Linkage of birth and infant death registration data have allowed information collected at the time of birth to be used for national monitoring of birthweight specific death rates. ${ }^{1}$ However between 1989 and 1993 there was a deterioration in the completeness of the birthweight data transferred to registrations, ${ }^{2}$ particularly for neonatal deaths.

Information on birth weight is collected by Registrars of Births, Deaths and Marriages from the statutory ${ }^{3}$ notification of births made by the midwife in attendance to the local Health Authority. If the birth is registered before the notification is received, it will not be entered on the draft birth certificate. There is little standardised information requested from midwives for birth notification, most of the form being at the discretion of the local Director of Public Health. The information is to provide health visitors with details of the birth, to generate a local child health record, and is also used to warn health visitors if a death has occurred.

This account illustrates the use of birth notification information to monitor birthweight specific infant death rates. The data is from computerised Community Child Health records in the 15 Districts that comprised the North Thames Regional Health Authority (East) (originally North East Thames Regional Health Authority-NETRHA). The data set was produced by a Regional project that started in 1991. It makes possible the estimation of stillbirth, neonatal, and postneonatal death rates by birthweight, and allows comparison with previously published national data.

\section{Methods}

COMMUNITY COMPUTERISED CHILD HEALTH DATA

In 1986 NETRHA, which had been a user of the National Child Health System, set up its own Regional Interactive Child Health System (RICHS). By 1989 all 15 districts in NETRHA used the same system, supported by a Regional Computer Centre. The basis for each record is the notification of a birth. Where the birth is to a resident of another district the information is copied and forwarded, although the district of birth should retain the information. Place of residence as well as hospital of birth is entered, so that records can be assigned either by place of residence, or by place of delivery.

AGGREGATION OF DISTRICT DATA

The birth notifications for all children born in the years 1989 to 1991 were downloaded in a standardised format with the help of the Regional Computer Centre. The retention of forwarded notifications means that when district data are aggregated, the regional data set includes duplicates. Before selecting records of births to residents a check was made of the 
Table 1 Completeness of linkage of records relating to stillbirths and infant deaths from RICHS records relating to residents of North Thames (East) and OPCS birth and death registration records for the birth cohorts 1989-1991

\begin{tabular}{|c|c|c|c|c|}
\hline \multirow{3}{*}{$\begin{array}{l}\text { Community child health records (RICHS) } \\
\text { Age at death }\end{array}$} & \multicolumn{4}{|c|}{ Records from death registrations } \\
\hline & \multicolumn{4}{|c|}{ Matches with RICHS } \\
\hline & SB & NND & PNND & Total \\
\hline SB & 794 & 2 & - & 796 \\
\hline NND & 3 & 701 & 1 & 705 \\
\hline PNND & - & - & 422 & 422 \\
\hline Inconsistent age & 5 & 17 & 8 & 30 \\
\hline Death date not recorded & 24 & 9 & 24 & 57 \\
\hline Total & 826 & 729 & 455 & 2010 \\
\hline Deaths expected from registrations & 842 & 755 & 472 & 2069 \\
\hline $\begin{array}{l}\text { Deaths apparently missing from child health sources } \\
(\%)\end{array}$ & $14(2)$ & $24(3)$ & $17(4)$ & $57(3)$ \\
\hline
\end{tabular}

$\mathrm{SB}=$ stillbirths, $\mathrm{NND}=$ neonatal deaths, $\mathrm{PNND}=$ postneonatal deaths.

consistency of data items relating to area of residence, including postcode. A single variable defining residence status at the time of birth was derived. This eliminated the problem of duplication of records. However particularly in these early years of RICHS data the completeness of recording of full postcode varied.

SELECTION OF DATA

The present account is based on records of births in 1989-1991 to mothers who were regional residents at the time of delivery, regardless of place of occurrence of the birth.

VALIDATION OF INFORMATION RELATING TO DEATHS

Stillbirths or infant deaths born between 1989 and 1991 to regional residents were ascertained from the Standard Regional Birth and Death Data sent to regions by the Office of Population Censuses and Surveys-OPCS (now part of the Office of National Statistics). A match for each of these stillbirths and infant death registrations was sought from RICHS records, searching on date of birth, date of death, infant sex, and multiplicity. Where there were unmatched deaths RICHS district managers were asked to carry out special searches of their own systems, an exercise that found some missing cases and enhanced the data of local systems.

RICHS records not identified as a death were assumed to be survivors and completed the denominators. RICHS records included 95 stillbirths, 19 neonatal, and four postneonatal deaths that were not found in the registrations. Many of these "stillbirths" were below registerable gestation and technically a late miscarriage. Some of these deaths occurred outside the UK or to US army personnel whose births and deaths are not registered in this country. All these 118 unmatched RICHS deaths have been excluded from the present data set.

CALCULATION OF DEATH RATES

Stillbirth rates are calculated by dividing by total births and expressed per 1000. Rates of neonatal death (before 28 days) and postneonatal deaths (between 28 and 365 days) were estimated by dividing these by live births and expressing the result per 1000 .
ANALYSIS

Matching and analysis was carried out using the Statistical Analysis System (SAS) and confidence intervals calculated using Stata software.

\section{CONFIDENTIALITY}

Agreement for setting up the aggregated Regional file of RICHS birth notification data was obtained from the local research ethics committee. Written agreement for release of data was obtained from each of the data custodians of the Child Health data. Data are held on a password protected mainframe computer, which does not include names or addresses and as far as possible all personal identifiers are obscured.

\section{Results}

VALIDATION OF DEATH MATCHING

Almost complete recording of deaths in the community child health system is demonstrated by the linkage summarised in table 1 , which found $826(97 \%)$ of stillbirths and 729 (96\%) neonatal and 455 (92\%) postneonatal deaths expected from registration sources.

Table 2 presents annual numbers of live births, stillbirths, neonatal, and postneonatal deaths in published OPCS tables ${ }^{2}$ and the RICHS data set. It should be noted that for years covered in this study published OPCS data are based on registrations in the calendar year, while the notification data relates to occurrences in the calendar year. ${ }^{4}$ The number of total live births in the two sets differ from each other by less than $1 \%$ in each of the three years shown. Although the correspondence varies a little by year and district, in the most recent year of this study, 1991, the difference never exceeded 3\%.

MOVEMENT BETWEEN DISTRICTS AND REGIONS The data can be used to study movements at the time of birth. For instance in 1991, where postcode information was fairly complete, $80 \%$ of the 57710 births, occurred in their district of residence, $17 \%$ elsewhere in the region and $3 \%$ outside the region.

\section{MISSING BIRTH WEIGHTS}

Between 1989 and 1991 only $0.1 \%$ of live birth notifications have missing or unlikely birth weights, compared with $4 \%$ of birth registrations (table 2). For stillbirths little difference in completeness over the years is found, with only slightly more complete recording of birthweight in the RICHS data. For infant deaths $4 \%$ of notifications were missing valid birth weight compared with $12 \%$ in registration data (table 2).

Multiple births account for $7 \%$ of RICHS records missing birth weight and known preterm births account for at least $17 \%$ (table 3) compared with an incidence of $1 \%$ and $6 \%$ respectively in all births. This disproportionate loss is not unexpected for infants likely to be transferred for intensive care immediately after birth and often before being weighed. The birth notification form would have been completed by the midwife usually in the labour 
Table 2 Comparison of numbers of births and deaths of North East Thames residents from OPCS and RICHS by birthweight group

\begin{tabular}{|c|c|c|c|c|c|c|c|c|}
\hline \multirow[b]{2}{*}{ Birthweight } & \multicolumn{2}{|c|}{ Stillbirths } & \multicolumn{2}{|c|}{ Live births } & \multicolumn{2}{|c|}{ Neonatal deaths } & \multicolumn{2}{|c|}{ Postneonatal deaths } \\
\hline & OPCS & RICHS & OPCS & RICHS & OPCS & RICHS & OPCS & RICHS \\
\hline \multicolumn{9}{|l|}{$<1500^{\star}$} \\
\hline 1989 & 67 & $67(4)$ & 562 & $577(18)$ & 115 & $128(8)$ & 28 & $25(0)$ \\
\hline 1990 & 69 & $71(6)$ & 527 & $595(37)$ & 98 & $124(9)$ & 21 & $26(0)$ \\
\hline 1991 & 74 & $74(4)$ & 602 & $683(52)$ & 120 & $137(9)$ & 22 & $26(0)$ \\
\hline \multicolumn{9}{|l|}{$1500-1999 \mathrm{~g}$} \\
\hline 1989 & 47 & 45 & 757 & 766 & 18 & 20 & 19 & 14 \\
\hline 1990 & 54 & 51 & 741 & 780 & 18 & 20 & 5 & 3 \\
\hline 1991 & 43 & 45 & 780 & 820 & 13 & 15 & 7 & 10 \\
\hline \multicolumn{9}{|l|}{$2000-2499 \mathrm{~g}$} \\
\hline 1989 & 35 & 38 & 2504 & 2525 & 21 & 25 & 16 & 16 \\
\hline 1990 & 55 & 54 & 2510 & 2578 & 12 & 16 & 15 & 15 \\
\hline 1991 & 40 & 41 & 2594 & 2696 & 14 & 16 & 18 & 16 \\
\hline \multicolumn{9}{|l|}{$2500 \mathrm{~g}+$} \\
\hline 1989 & 103 & 101 & 50407 & 51778 & 71 & 75 & 139 & 117 \\
\hline 1990 & 124 & 128 & 51224 & 53515 & 63 & 66 & 97 & 99 \\
\hline 1991 & 100 & 102 & 50597 & 53165 & 52 & 56 & 76 & 67 \\
\hline \multicolumn{9}{|c|}{ Missing birthweight $\dagger$} \\
\hline 1989 & 14 & 4 & 1864 & 67 & 35 & 6 & 3 & 7 \\
\hline 1990 & 13 & 3 & 3101 & 65 & 44 & 6 & 15 & 4 \\
\hline 1991 & 14 & 2 & 2486 & 80 & 45 & 19 & 11 & 10 \\
\hline \multicolumn{9}{|c|}{ All birthweights including missing } \\
\hline 1989 & 266 & 255 & 56094 & 55720 & 260 & 254 & 205 & 179 \\
\hline 1990 & 315 & 307 & 57999 & 57537 & 235 & 232 & 153 & 147 \\
\hline 1991 & 271 & 264 & 57079 & 57444 & 244 & 243 & 134 & 129 \\
\hline
\end{tabular}

*The number of RICHS records with weights $<500 \mathrm{~g}$ are shown in parentheses.

†This category includes missing and null birth weights.

ward. It follows that infant death rates in the lowest weight groups are likely to be understated unless special efforts are made to seek birth weights of infants admitted for special or intensive care.

BIRTH WEIGHTS OF LESS THAN $500 \mathrm{~g}$

Details of 121 births with recorded weights of less than $500 \mathrm{~g}$ (shown in parentheses in table 2) are given in table 3 . There were 71 reported survivors weighing less than $500 \mathrm{~g}$, apparently born at term, which almost certainly represent errors in recording birth weight. Further work to validate and update these data is feasible, given the small numbers involved and would provide valuable information about survival at such very low birth weights.
BIRTHWEIGHT SPECIFIC COMPARISONS BETWEEN REGISTRATIONS AND BIRTH NOTIFICATIONS

The distribution of birth weights are comparable for stillbirths in the two sources (table 2). There are however differences in the numbers of live birth records allocated to the different birthweight groups, with 164 more live births and 62 more infant deaths in the notification data identified as of very low birth weight compared with registration data. The better completed data from birth notifications suggest that birthweight specific estimates from this source, particularly at the lower extremes, are likely to be more informative. These are presented in table 4 for $500 \mathrm{~g}$ groups, which gives more detail than is available from routinely published OPCS data.

Table 3 Characteristics of notifications of births weighing less than $500 \mathrm{~g}$ at birth

\begin{tabular}{|c|c|c|c|c|c|c|}
\hline \multirow[b]{2}{*}{ Stillbirth infant characteristics } & \multicolumn{6}{|c|}{ Birthweight } \\
\hline & 0 & $1-$ & 100 & 200 & $300-$ & $400-499$ \\
\hline Stillbirths & 9 & 1 & 1 & 1 & 4 & 7 \\
\hline 1989 & 4 & 0 & 0 & 0 & 1 & 3 \\
\hline 1990 & 3 & 0 & 1 & 0 & 2 & 3 \\
\hline 1991 & 2 & 1 & 0 & 1 & 1 & 1 \\
\hline Neonatal deaths & 31 & 4 & 0 & 2 & 1 & 19 \\
\hline 1989 & 6 & 2 & 0 & 1 & 0 & 5 \\
\hline 1990 & 6 & 0 & 0 & 0 & 1 & 8 \\
\hline 1991 & 19 & 2 & 0 & 1 & 0 & 6 \\
\hline Postneonatal deaths & 21 & 0 & 0 & 0 & 0 & 0 \\
\hline 1989 & 7 & 0 & 0 & 0 & 0 & 0 \\
\hline 1990 & 4 & 0 & 0 & 0 & 0 & 0 \\
\hline 1991 & 10 & 0 & 0 & 0 & 0 & 0 \\
\hline Survivors & 160 & 12 & 7 & 12 & 41 & 9 \\
\hline 1989 & 54 & 1 & 1 & 0 & 6 & 2 \\
\hline 1990 & 55 & 6 & 4 & 3 & 13 & 2 \\
\hline 1991 & 51 & 5 & 2 & 9 & 22 & 5 \\
\hline \multicolumn{7}{|l|}{ Plurality ${ }^{\star}$} \\
\hline missing & $15(13)$ & 0 & 0 & 0 & 0 & 0 \\
\hline singleton & $191(40)$ & $14(0)$ & $5(2)$ & $13(2)$ & $43(2)$ & $26(17)$ \\
\hline twin and higher order & $15(8)$ & $3(1)$ & $3(1)$ & $2(3)$ & $3(3)$ & $9(9)$ \\
\hline \multicolumn{7}{|l|}{ Gestation^ } \\
\hline missing & $76(17)$ & $2(2)$ & 0 & $1(0)$ & 0 & 0 \\
\hline$<28$ & $9(7)$ & $4(3)$ & 0 & $1(1)$ & $1(1)$ & $18(18)$ \\
\hline $28-36$ & $29(11)$ & $1(0)$ & $7(0)$ & $2(1)$ & $3(3)$ & $6(6)$ \\
\hline $37+$ & $107(26)$ & $10(0)$ & $1(1)$ & $11(1)$ & $42(1)$ & $11(1)$ \\
\hline Total & $221(61)$ & $17(5)$ & $8(1)$ & $15(3)$ & $46(5)$ & $35(26)$ \\
\hline
\end{tabular}

${ }^{\star}$ Number of deaths given in parentheses. 
TRENDS OVER TIME: STILLBIRTH RATES

There is no appreciable trend in birthweight specific rates of stillbirths over time. Numbers and rates of stillbirths in the lowest weight groups are limited by the definition of stillbirths in operation at that time, which included only those of 28 weeks gestation or more, in contrast with live births, which include all cases irrespective of gestation.

TRENDS OVER TIME: INFANT DEATH RATES

Although there are small fluctuations, the trend in infant mortality trend over time is downwards in all birthweight groups. As reported from national data $^{3}$ the most pronounced change has been the fall in the postneonatal death rate (28\%) between 1989 and 1991, although neonatal mortality also fell by $9 \%$ (table 4). The reduction is most evident in the babies of 3000-3999 g, where the infant death rate in 1991 was half of that in 1989.

Only $1 \%$ of births in each of the years was recorded as weighing less than $1500 \mathrm{~g}$. There is a gradual increase in the numbers and incidence of livebirths weighing less than 1000 $\mathrm{g}$ over the three years. There were small improvements in their survival to age one year from 1989 to $1991,10 \%$ in the lowest weight group, $13 \%$ for infants weighing 1000-1499 g. Three quarters of single and multiple births weighing 900 to $999 \mathrm{~g}$ survived infancy.
In contrast, for babies weighing more than $4000 \mathrm{~g}$ there seems to be a deterioration in rates of survival, most noticeable for neonatal mortality where rates have risen by a factor of 3.5 from 0.4 to 1.4 deaths per 1000 live births. Such births represent about $10 \%$ of all births and increased almost $10 \%$ over the three years. The numbers of deaths are sparse and rates are therefore likely to be unstable, so some caution needs to be exercised in interpreting these results.

BIRTHWEIGHT SPECIFIC OUTCOME FOR

SINGLETON AND MULTIPLE BIRTHS

One of the major factors confounding rates of mortality for very small infants is plurality. Multiple births accounted for almost $20 \%$ of the births under $1500 \mathrm{~g}$ and overall exhibit substantially higher mortality. Table 5 shows that with the exception of the groups weighing 900-999 $\mathrm{g}$ and 1400-1499 $\mathrm{g}$, the infant death rates of the multiple births was higher than that of the singletons. However the numbers are small and the variations correspondingly large.

Comparison with the most recently published corresponding data from England and Wales ${ }^{1}$ for 1987 , shows that for single and multiple births of all but the two lowest weight groups, the infant mortality is consistently and considerably lower in the RICHS data.

Table 4 Birthweight specific death rates of North East Thames residents:RICHS data

\begin{tabular}{|c|c|c|c|c|c|c|c|c|c|}
\hline \multirow[b]{2}{*}{ Birth weight ( $g$ ) } & \multicolumn{2}{|c|}{$\begin{array}{l}\text { Stillbirths } 28+ \\
\text { weeks }\end{array}$} & \multirow{2}{*}{$\begin{array}{l}\begin{array}{l}\text { Live } \\
\text { births }\end{array} \\
\text { No }\end{array}$} & \multicolumn{2}{|c|}{ Neonatal deaths } & \multicolumn{2}{|c|}{$\begin{array}{l}\text { Postneonatal } \\
\text { deaths }\end{array}$} & \multicolumn{2}{|c|}{ Infant deaths } \\
\hline & No & Rate & & No & Rate & No & Rate & No & Rate \\
\hline \multicolumn{10}{|l|}{$500-$} \\
\hline 1989 & 25 & 111.1 & 200 & 83 & 415.0 & 15 & 75.0 & 98 & 490.0 \\
\hline 1990 & 23 & 110.0 & 219 & 86 & 392.7 & 12 & 54.8 & 98 & 447.5 \\
\hline 1991 & 19 & 70.1 & 252 & 94 & 373.9 & 17 & 67.5 & 111 & 440.5 \\
\hline \multicolumn{10}{|l|}{$1000-$} \\
\hline 1989 & 38 & 95.7 & 359 & 37 & 103.1 & 10 & 27.9 & 47 & 130.9 \\
\hline 1990 & 42 & 110.2 & 339 & 29 & 85.5 & 14 & 41.3 & 43 & 126.8 \\
\hline \multirow{2}{*}{\multicolumn{10}{|c|}{$1500-$}} \\
\hline & & & & & & & & & \\
\hline 1989 & 45 & 55.5 & 766 & 20 & 26.1 & 14 & 18.3 & 34 & 44.4 \\
\hline 1990 & 51 & 61.4 & 780 & 20 & 25.6 & 3 & 3.8 & 23 & 29.3 \\
\hline 1991 & 45 & 52.0 & 820 & 15 & 18.3 & 10 & 12.2 & 25 & 30.5 \\
\hline \multicolumn{10}{|l|}{$2000-$} \\
\hline 1989 & 38 & 14.8 & 2525 & 25 & 9.9 & 16 & 6.3 & 41 & 16.2 \\
\hline 1990 & 54 & 20.5 & 2578 & 16 & 6.2 & 15 & 5.8 & 31 & 12.0 \\
\hline 1991 & 41 & 15.0 & 2696 & 16 & 5.9 & 16 & 5.9 & 32 & 11.9 \\
\hline \multicolumn{10}{|l|}{$2500-$} \\
\hline 1989 & 46 & 4.4 & 10423 & 25 & 2.4 & 35 & 3.4 & 60 & 5.8 \\
\hline 1990 & 42 & 4.0 & 10555 & 23 & 2.2 & 28 & 2.7 & 51 & 4.9 \\
\hline 1991 & 39 & 3.7 & 10421 & 18 & 1.7 & 19 & 1.8 & 37 & 3.6 \\
\hline \multicolumn{10}{|l|}{$3000-$} \\
\hline 1989 & 27 & 1.3 & 20954 & 23 & 1.1 & 46 & 2.2 & 69 & 3.3 \\
\hline 1990 & 50 & 2.3 & 21624 & 21 & 1.0 & 40 & 1.8 & 61 & 2.8 \\
\hline 1991 & 27 & 1.3 & 21441 & 17 & 0.8 & 24 & 1.1 & 41 & 1.9 \\
\hline \multicolumn{10}{|l|}{$3500-$} \\
\hline 1989 & 19 & 1.2 & 15331 & 25 & 1.6 & 30 & 2.0 & 55 & 3.6 \\
\hline 1990 & 24 & 1.5 & 15906 & 17 & 1.1 & 24 & 1.5 & 41 & 2.6 \\
\hline 1991 & 25 & 1.6 & 15763 & 13 & 0.8 & 17 & 1.1 & 30 & 1.9 \\
\hline \multicolumn{10}{|l|}{$4000-7999$} \\
\hline 1989 & 9 & 1.8 & 5070 & 2 & 0.4 & 6 & 1.2 & 8 & 1.6 \\
\hline 1990 & 12 & 2.2 & 5430 & 5 & 0.9 & 7 & 1.3 & 12 & 2.2 \\
\hline 1991 & 11 & 2.0 & 5540 & 8 & 1.4 & 7 & 1.3 & 15 & 2.7 \\
\hline \multicolumn{10}{|c|}{$\begin{array}{l}\text { Missing birth weight and out of } \\
\text { range }\end{array}$} \\
\hline 1989 & 8 & & 92 & 14 & & 7 & & 21 & \\
\hline 1990 & 9 & & 106 & 15 & & 4 & & 19 & \\
\hline 1991 & 6 & & 132 & 28 & & 10 & & 38 & \\
\hline \multicolumn{10}{|c|}{ All including missing } \\
\hline 1989 & 255 & 4.6 & 55720 & 254 & 4.6 & 179 & 3.2 & 433 & 7.8 \\
\hline 1990 & 307 & 5.3 & 57537 & 232 & 4.0 & 147 & 2.6 & 379 & 6.6 \\
\hline 1991 & 264 & 4.6 & 57444 & 243 & 4.2 & 129 & 2.3 & 372 & 6.5 \\
\hline
\end{tabular}

Stillbirth rates are calculated per 1000 total births; neonatal and postneonatal mortality per 1000 live births. 


\section{Discussion}

The main aim of this paper has been to show the use of birth notification data for the monitoring of stillbirth and infant death rates. Validation of the data showed that the number of deaths that could not be matched with birth registration data was small. Moreover, these were compensated for by the greater number with known birthweight in the notification data. The failure to record birth weight in registration data tends to be administrative, the baby being registered before the registrar receives details from the birth notification. As shown in this paper, the unrecorded birth weights in the notifications themselves are more often found in babies likely to have been transferred to neonatal units, a fact that needs to be noted when comparing death rates of high risk infants.

The use of these local data allows an increased flexibility of tabulations. As shown here these can be produced in $100 \mathrm{~g}$ groups, to enable ongoing monitoring of survival at very low birth weight. Moreover survivors of such low birth weights can be identified, thus helping their follow up, and the planning of the resources needed for the care of those at risk of subsequent disability. ${ }^{5}$

The present exercise has shown that this work has been worthwhile in providing an information system that derives directly from available data without further data collection. While similar results have been obtained from special surveys, ${ }^{6}$ this to our knowledge, is the first time routinely collected data has used for surveillance at regional level. The data linkage and editing, costing $£ 125000$ over three years to establish, has been continued with far more modest resources. Regular reports are available to purchasing teams and maternity service providers, and the data can be used as denominator data for programmes such as the Confidential Enquiry for Stillbirths and Deaths in Infancy (CESDI).
The fact that the latest data in this report relate to 1991 is because of the changes that took place in the provision of data to the regions by OPCS, who no longer provide regional data sets, and the change to the regional structure. For the validation of infant, particularly postneonatal deaths, to a birth cohort it is necessary to have available data on all deaths occurring in the next calendar year, as some will occur in the year after that of their birth. Moreover, after 1992 there were many changes in the data processing at OPCS, which held up the release of information. In the future this exercise will be repeated so that updated information will be available.

In other European countries there are concerns with the timeliness of publication of perinatal statistics. ${ }^{8}$ In England and Wales, where detailed reports are produced annually, normally within two years, the limitation lies in the restricted range of details collected at birth registration. Use of the notification system enables registration data to be supplemented with additional information about outcomes such as gestational age specific mortality ${ }^{9}$ and process of obstetric care such as gestation at booking, instrumental and operative delivery, and method of resuscitation. These are a necessary basis for comparative clinical audit. National data are at the present too incomplete to be able to calculate meaningful estimates.

The maintenance of high quality standardisation and compatibility of child health data over as wide a range as possible of health authorities and provider units is essential if these valuable data, in part collected on a statutory basis can continue to be used for audit and planning purposes. Unfortunately few regions have been as far sighted as the North Thames (East), many district providers being tempted to purchase incompatible data collection systems, which lead to fragmentation of the data base. As many births occur outside the district of residence this fragmentation makes it impossible to meet the government

Table 5 Birthweight specific mortality of infants born to residents of NETRHA 1989-1991 categorised by multiple birth status and compared with published national data

\begin{tabular}{|c|c|c|c|c|c|c|c|c|c|c|c|c|}
\hline \multirow[b]{3}{*}{ Birth weight $(g)$} & \multicolumn{6}{|c|}{ Number of live births (LB) and infant deaths (ID) } & \multicolumn{6}{|c|}{ Infant death rates and $95 \%$ confidence intervals } \\
\hline & \multicolumn{2}{|c|}{ Singleton births } & \multicolumn{2}{|c|}{$\begin{array}{l}\text { Multiple } \\
\text { births }\end{array}$} & \multicolumn{2}{|c|}{$\begin{array}{l}\text { Missing multiple } \\
\text { birth status }\end{array}$} & \multirow{2}{*}{$\begin{array}{l}\text { Singleton births } \\
\text { England and } \\
\text { Wales } 1987\end{array}$} & \multicolumn{2}{|c|}{$N T$ (E) 1989-1991 } & \multirow{2}{*}{$\begin{array}{l}\text { Multiple births } \\
\text { England and } \\
\text { Wales } 1987 \\
\text { IMR }\end{array}$} & \multicolumn{2}{|c|}{$N T$ (E) 1989-1991 } \\
\hline & $L B$ & $I D$ & $L B$ & $I D$ & $L B$ & $I D$ & & $I M R$ & $95 \% C I$ & & $I M R$ & $95 \% C I$ \\
\hline $500-599$ & 76 & 52 & 13 & 13 & 0 & 0 & 804 & 684 & $567.2,785.9$ & 933 & 1000 & $732.0,1000^{\star}$ \\
\hline $600-699$ & 94 & 57 & 22 & 21 & 0 & 0 & 793 & 606 & $500.3,705.5$ & 862 & 955 & $771.1,999.8$ \\
\hline $700-799$ & 110 & 46 & 10 & 7 & 1 & 1 & 567 & 418 & $342.8,515.9$ & 727 & 700 & $347.2,933.2$ \\
\hline $800-899$ & 151 & 53 & 23 & 12 & 1 & 1 & 449 & 351 & $252.2,432.7$ & 751 & 522 & $305.7,731.9$ \\
\hline 900-999 & 139 & 36 & 31 & 8 & 0 & 0 & 323 & 259 & $188.4,340.4$ & 403 & 258 & $111.8,446.1$ \\
\hline $1000-1099$ & 124 & 27 & 24 & 7 & 1 & 1 & 289 & 218 & $148.6,300.6$ & 288 & 292 & $126.2,510.9$ \\
\hline $1100-1199$ & 164 & 31 & 38 & 10 & 2 & 2 & 206 & 189 & $132.1,257.5$ & 225 & 263 & $134.1,430.8$ \\
\hline $1200-1299$ & 171 & 12 & 43 & 5 & 0 & 0 & 155 & 70 & $36.1,119.4$ & 202 & 116 & $38.8,250.9$ \\
\hline $1300-1399$ & 177 & 12 & 58 & 9 & 0 & 0 & 128 & 68 & $35.4,115.3$ & 80 & 155 & $73.4,274.4$ \\
\hline $1400-1499$ & 217 & 16 & 58 & 1 & 0 & 0 & 111 & 74 & $42.7,116.9$ & 61 & 17 & $4.4,92.3$ \\
\hline $1500-1999$ & 1728 & 72 & 634 & 9 & 4 & 1 & 69 & 42 & $32.7,52.2$ & 29 & 14 & $6.5,26.7$ \\
\hline $2000-2499$ & 6494 & 87 & 1304 & 17 & 1 & 0 & 17 & 13 & $10.7,16.5$ & 12 & 13 & $7.6,20.8$ \\
\hline $2500-2999$ & 30079 & 138 & 1313 & 8 & 7 & 2 & 5 & 5 & $3.9,5.4$ & 12 & 6 & $2.6,12.0$ \\
\hline $3000-3499$ & 63518 & 168 & 489 & 3 & 12 & 0 & 2 & 3 & $2.3,3.1$ & 8 & 6 & $1.3,17.8$ \\
\hline $3500+$ & 62943 & 160 & 93 & 2 & 4 & 0 & 1 & 3 & $2.2,3.0$ & 10 & 22 & $2.6,75.5$ \\
\hline $\begin{array}{l}\text { Birth weight missing or } \\
\text { out of range }\end{array}$ & 287 & 50 & 28 & 16 & 15 & 12 & & & & & & \\
\hline Total & $<16472$ & 1017 & 4181 & 147 & 48 & 20 & & 6 & $5.7,6.5$ & & 35 & $29.8,41.9$ \\
\hline
\end{tabular}

$\star$ One tailed test. 
KEY POINTS

- The increasing demand for data relating to outcomes of maternity services suggests alternative sources of data need to be explored to meet current requirements. Birth notification data are a universal source of such information, if these can be aggregated and shown to be of sufficient quality.

- Notification data provides more complete data on birth weight and can be used to provide more detailed and timely information than that available at the present time from birth registration sources. The use of record linkage provides a means of quality assurance and a possible mechanism for improving national data.

- Special efforts need to be made to counter the loss of birthweight data relating to very small and very ill infants transferred to neonatal units immediately after birth, before being weighed.

- A wider range of birthweight grouping than that routinely published by OPCS is required to effectively monitor the changes in still birth and infant mortality at the extremes of birth weight.

- The increasing survival of infants at the lower extremes of birth weight requires ongoing scrutiny in view of their high risk of disability.

requirements that planners and consumers should have access to population based information regarding the quality and outcome of maternity services. Analyses of birth information by district of occurrence is possible in these but confounded by patient selection by different hospitals, and comparisons between districts become difficult. The present report has shown the use of aggregated data to review births data for residents of a regional level.
Annual tables of birth notifications are produced by RICHS for residents of each district and for the commissioning authorities, and it is planned soon to add mortality data for more recent years.

The attention of Maternity Services Liaison Committees should be drawn to the importance of such data for their work and consideration should be given to the possibility of increasing data exchange between the birth notification and birth registrations systems. There is already provision for such exchanges. ${ }^{10}$

This work was supported by the District and Regional Health Authorities of NETRHA and would not have been possible without the help of the District Child Health teams, the Regional Computer Centre and the many managers of provider units who contributed generously of their time. Thanks is due also to Carmel Ryan for secretarial assistance, Alan MacIntosh for computer assistance, and to the members of the Steering Group who provided helpful advice throughout the project.

Group who provided helpful advice throughout the project.
Funding: this work was funded initially by NETRHA, but Funding: this work was funded initially by NETRHA, but
subsequently was supported jointly by NETRHA (later the North Thames Regional Health Authority) and individual hospitals and district health authorities situated in the eastern part of the region.

1 Alberman E, Botting B. Trends in prevalence and survival of very low birthweight infants, England and Wales:1983-7. Arch Dis Child 1991:66:1304-8.

2 Office of Population Censuses and Surveys. Mortality Statistics - perinatal and infant: social and biological factors. Annual reviews. England and Wales 1990, 1991, 1992.Series DH3 Nos.23-25. London, HMSO.

3 National Health Service Act 1977, s124. London, HMSO.

4 Office for National Statistics. Mortality statistics - childhood, infant and perinatal. Annual review. England and Wales 1993 and 1994. Series DH3 No.27. London: The Stationery Office, 1996.

5 National Perinatal Epidemiology Unit and Oxford Regional Health Authority. Disability and perinatal care: measurement of health status at 2 years. Oxford: March 1994.

6 All Wales perinatal survey and confidential enquiry into All Wales perinatal survey and confidential enquiry into
stillbirths and deaths in infancy. Annual Report 1994. Perinastillbirths and deaths in infancy. Annual Report 1994. Perina-
tal Survey Office, Department of Child Health. Cardiff: tal Survey Office, Department of Child
University of Wales College of Medicine.

7 Information and Statistics Division, Directorate of Information Services: the NHS in Scotland. Birthweight, gestation and deaths in the first year: Scotland 1990. Edinburgh: ISD Publications, 1993.

8 Tafforeau JM, Van Oyen H, Drieskens S. Perinatal epidemiology in Belgium. European fournal of Public Health 1995;6: 133-6.

9 Hilder AS, Costello K, Thiliganathan B. Post-term pregnancy: a new perspective on evaluation of gestationspecific risk of fetal and infant mortality. Br F Obstet Gynaecol (in press).

10 Department of Health. An information management and technology strategy for the NHS in England. IMG of the NHSME. London, HMSO, 1993. 